\title{
VALIDITAS PERANGKAT PEMBELAJARAN BERBASIS CCM-CCA PADA MATERI DINAMIKA PARTIKEL
}

\section{VALIDITY OF CCM-CCA BASED LEARNING DEVICE IN PARTICLE DYNAMICS CHAPTER}

\author{
Muh. Makhrus, Wahyudi, Muhammad Taufik, Muhammad Zuhdi \\ Program Studi Pendidikan Fisika FKIP Universitas Mataram, Mataram, Indonesia \\ Email: makhrus.fkip@unram.ac.id
}

Diterima : 02 November 2019. Disetujui : 02 Desember 2019. Dipublikasikan: 31 Januari 2020

\begin{abstract}
Abstrak: Kesalahan konsep sering didasarkan pada pengalaman pribadi dan sulit untuk berubah ke pemahaman konten ilmiahnya, bahkan setelah pembelajaran dirancang untuk menangani konten ilmiah di mana kesalahan konsep terjadi, banyak mahasiswa tidak merekonstruksi pemikirannya. Mahasiswa yang mampu merekonstruksi pengetahuan (perubahan konseptual) adalah yang menggunakan pemikiran kritis dan penalaran logis. Konflik kognitif memiliki peran penting dalam terjadinya perubahan konseptual. Seorang pendidik yang dapat meyakinkan peserta didik bahwa konsepsi-konsepsi fisika yang dimiliki merupakan konsepsi yang salah (miskonsepsi), maka mahasiswa akan yakin bahwa dia membutuhkan perubahan konseptual. Berdasarkan hal tersebut, penelitian ini bertujuan mengembangkan perangkat pembelajaran berbasis model pembelajaran CCM CCA (Concetual Change Model with Cognitive Conflict Approach) sebagai suatu produk yang valid beserta instrumennya yang akan dapat memfasilitasi terjadinya perubahan konseptual pada mahasiswa. Perangkat pembelajaran yang dikembangkan mencakup materi dinamika partikel yang terdiri dari hukum Newton dan Usaha-Energi dengan masing-masing materi memiliki 3 SAP dan 3 LKM. Validasi perangkat pembelajaran secara isi dan konstruk dilakukan dengan teknik FGD (Focused Group Discussions) oleh ahli (expert) di bidang pendidikan fisika. Hasil validasi perangkat pembelajaran menunjukkan bahwa perangkat pembelajaran CCMCCA yang dikembangkan layak (valid) digunakan pada pembelajaran fisika dasar dengan melakukan sedikit revisi berdasarkan saran/masukan dari peserta FGD.
\end{abstract}

Kata Kunci: Perangkat pembelajaran, Model pembelajaran CCM-CCA, Dinamika partikel

\begin{abstract}
Conceptual errors usually based on personal experience and it is difficult to be changed to the true conception of scientific content. Even after learning is designed to deal with scientific content where concept errors occur, many students do not reconstruct their thinking. Students who can reconstruct knowledge (conceptual change) are those who use critical thinking and logical reasoning. The cognitive conflict has an important role in the occurrence of conceptual change. An educator who can convince students that their conceptions of physics are wrong conceptions (misconceptions), then students will be sure that they need conceptual change. Based on this, this study aims to develop learning device based on the CCM CCA (Conceptual Change Model with Cognitive Conflict Approach) learning model as a valid product and its instruments that will facilitate the conceptual change in students. The learning devices developed include particle dynamics material consisting of Newton's law and Business-Energy with each material having three LEU (Learning Events Units) and three SW (Student's Worksheet). Validation of instructional devices in content and construct is done by FGD (Focused Group Discussions) techniques by experts in the field of physics education. The results of the validation of the learning kit show that the CCM-CCA learning kit developed is valid for basic physics learning by making a few revisions based on suggestions and input from FGD participants.
\end{abstract}

Keywords: Learning device, CCM-CCA learning model, dynamic particle

\section{PENDAHULUAN}

Konflik kognitif memiliki peran penting dalam terjadinya perubahan konseptual. Seorang pengajar yang dapat meyakinkan peserta didik bahwa konsepsi-konsepsi yang dimiliki adalah merupakan konsepsi yang salah (miskonsepsi), maka peserta didik akan yakin bahwa dia membutuhkan perubahan. Pembelajaran melalui model perubahan konseptual dengan pendekatan konflik kognitif (model pembelajaran CCM CCA) merupakan suatu model pembelajaran yang dapat membantu peserta didik dalam membangun pengetahuannya sendiri, karena keterlibatan peserta didik selama proses pembelajaran. Pembelajaran melalui model perubahan konseptual dengan pendekatan konflik kognitif (model pembelajaran CCM CCA) akan menghubungkan peserta didik dalam pembelajaran aktif, dari tahapan pertama pembelajaran [1]. Pada kasus tertentu, tantangan yang diberikan akan disajikan pada permulaan pembelajaran yaitu dengan meminta peserta didik untuk membuat sebuah penalaran atas prediksi dan estimasi, atau 
untuk menjelaskan strategi yang akan mereka gunakan untuk mendekati permasalahan. Mereka juga akan diminta untuk mendukung pandangan mereka dalam sebuah pernyataan tertulis, gambar atau model fisika.

Perubahan konseptual dapat terjadi, jika pengetahuan sebelumnya dipertemukan dengan informasi baru (dikonflikkan). Pada saat pengetahuan sebelumnya berkonflik dengan informasi baru yang diterima pada saat pembelajaran, maka pengetahuan tersebut merupakan kepercayaan yang salah. Kepercayaan yang salah dan informasi yang benar akan berkonflik secara kontradiktif, sehingga pendesainan pengajaran yang memiliki target pada pembuktian kepercayaan yang salah mungkin akan dapat mengkoreksi kepercayaan peserta didik, sehingga menciptakan sebuah pembaruan kepercayaan. Hal ini sesuai dengan pernyataan bahwa kepercayaan yang salah pada materi pelajaran dapat dikoreksi ketika peserta didik dikonfrontasikan secara eksplisit dengan informasi yang benar melalui kontradiksi dan refutasi (pembuktian) [2]. Hal ini menunjukkan bahwa konflik kognitif memainkan sebuah peran atau efek penting dalam perubahan konseptual. Kebutuhan akan pentingnya konflik kognitif untuk membuat perubahan konseptual terjadi [3].

Peserta didik mengalami proses asimilasi dan akomodasi dalam proses pembelajaran, sehingga peserta didik setiap saat membangun pengetahuannya sampai konsep yang dipahaminya tidak bertentangan dengan konsep para ilmuwan. Ada dua proses yang terjadi dalam perkembangan dan pertumbuhan kognitif anak yaitu: (1) proses "assimilation", dalam proses ini menyesuaikan dan mencocokkan informasi yang baru dengan apa yang telah diketahui; dan (2) proses "accommodation" yaitu anak menyusun dan membangun kembali atau mengubah apa yang telah diketahui sebelumnya, sehingga informasi yang baru itu dapat disesuaikan dengan yang lebih baik [4]. Agar proses asimilasi dan akomodasi dapat benar-benar memuaskan peserta didik, maka rangsangan konflik kognitif sangat diperlukan [5]. Rangsangan tersebut dapat berupa penjelasan dan demonstrasi berupa contohcontoh yang kontradiksi dengan pemahaman peserta didik. Kegiatan selanjutnya, peserta didik diberikan kesempatan untuk melakukan kegiatan berpikir ilmiah dan melakukan penyelidikan melalui eksperimen untuk membuktikan kebenaran konsepkonsep yang telah dimiliki dan konsep-konsep yang kontradiksi dengan konsepsi peserta didik tersebut dengan harapan dapat membangun ulang/merekonstruksi pemikiran mereka, sehingga miskonsepsi-miskonsepsi yang mereka miliki dapat dihilangkan.

Tujuan utama dari pembelajaran dengan CCM CCA adalah membantu peserta didik untuk mengembangkan kemampuan berpikir ilmiah, membangun pemahaman konseptual yang benar, dan melakukan penerapan terhadap konsep-konsep yang telah dimiliki, dengan demikian pembelajaran akan menjadi bermakna. Fase pembelajaran CCM CCA terdiri dari 7 (tujuh) fase pembelajaran, yaitu: (1) menyajikan konteks masalah atau menciptakan konflik kognitif (preliminary), (2) menentukan hasil atau posisi (commit to a position or outcome), (3) mengekspos kepercayaan (exposebeliefs), (4) menciptakan konflik kognitif (cognitive conflict), (5) mengakomodasi dan memperluas konsepkonsep (acommodate and extend the concepts), (6) penyelesaian atau pengujian masalah (resolution), dan (7) evaluasi (evaluation) [6].

Berdasarkan uraian di atas, target khusus dalam penelitian ini adalah mengembangkan perangkat pembelajaran berbasis model pembelajaran CCM CCA (Concetual Change Model with Cognitive Conflict Approach) pada materi dinamika partikel mata kuliah fisika dasar sebagai suatu produk yang valid beserta instrumennya, sehingga layak digunakan dalam pembelajaran dan menambah alternatif desain pembelajaran. Validasi perangkat pembelajaran secara isi dan konstruk akan dilakukan dalam kegiatan FGD (Focused Group Discussions) oleh ahli (expert) di bidang pendidikan fisika.

\section{METODE PENELITIAN}

Desain penelitian dalam penelitian ini mengikuti tahap-tahap Education Research and Development. Metode ini digunakan untuk menghasilkan produk tertentu dan menguji keefektifan produk tersebut. Produk tersebut adalah perangkat pembelajaran berbasis model pembelajaran CCM CCA yang valid, praktis, dan efektif berikut instrumen penelitiannya [7]. Pengembangan model dimulai dari mendesain model sampai implementasi model. Secara konseptual metode penelitian R \& D meliputi 10 tahapan kegiatan kemudian diadaptasi dan menghasilkan 4 tahap, yaitu: 1) studi pendahuluan, 2) penyusunan perangkat pembelajaran, 3) validasi perangkat pembelajaran, 4) imlementasi perangkat pembelajaran pada pembelajaran dengan menggunakan model CCM CCA [8].

Perangkat pembelajaran yang dikembangkan dinilai kriteria/aspek dari instrumen penilaian perangkat yang telah dikembangkan. Hasil penilaian pada kegiatan FGD yang dilakukan oleh 3 orang ahli (expert) di bidang fisika dan pendidikan akan dikonversikan ke dalam Tabel 1 berikut ini. 
Tabel 1. Kriteria Validitas Perangkat Pembelajaran CCM-CCA

\begin{tabular}{cl|l}
\hline Interval Skor Validitas & \multicolumn{1}{c|}{ Kategori } & \multicolumn{1}{c}{ Keterangan } \\
\hline $1 \leq$ Skor $<1,75$ & Kurang Valid & Dapat digunakan dengan banyak revisi \\
$1,75 \leq$ Skor $<2,50$ & Cukup Valid & Dapat digunakan dengan cukup banyak revisi \\
$2,50 \leq$ Skor $<3,25$ & Valid & Dapat digunakan dengan sedikit revisi \\
$3,25 \leq$ Skor 4,00 & Sangat Valid & Dapat digunakan tanpa revisi \\
\hline
\end{tabular}

Reliabilitas perangkat pembelajaran CCM-CCA yang dikembangkan dianalisis menggunakan analisis statistik "Percentage of Agreement" yaitu

$$
\text { Reliabilitas }=\left[1-\frac{(A-B)}{(A+B)}\right] \times 100 \%
$$

Dengan A adalah skor tertinggi validator dan B merupakan skor terendah validator. Perangkat pembelajaran dikatakan reliabel jika nilai reliabilitasnya lebih besar dari 75\% [1].

\section{HASIL DAN PEMBAHASAN}

Hasil Validitas perangkat pembelajaran ini berdasarkan hasil analisis penilaian perangkat pembelajaran dengan instrumen penilaian. Rencana pelaksanaan pembelajaran (SAP) dinilai berdasarkan pada 5 komponen penting pengembangan SAP yaitu 1) Penyusunan dan pengembangan kompetensi dasar, tujuan pembelajaran, dan indikator pencapaian kompetensi; 2) Penyajian dan pengembangan materi pembelajaran yang relevan; 3) Kesesuain antara metode, model, dan media pembelajaran yang digunakan; 4) Penyusunan kegiatan/langkah pembelajaran sesuai sintaks dan sesuai aturan K13; 5) ketepatan waktu dengan kegiatan pembelajaran dan pemilihan instrumen evaluasi pembelajaran. Sedangkan untuk lembar kerja mahasiswa (LKM) dinilai berdasarkan 5 komponen yaitu 1) Materi mengacu pada SAP yang dikembangkan dan sesuai dengan karakteristik model yang digunakan; 2) Aktivitas yang dilakukan sesuai sintaks model pembelajaran dan memperlihatkan aktivitas konflik kognitif; 3) Kegiatan pada LKM cocok untuk meningkatkan kemampuan berpikir tingkat tinggi (HOTS); 4) Bahasa yang digunakan merupakan bahasa yang baik dan benar; 5) Alokasi waktu sesuai dengan permasalahan yang ada pada LKM. Berdasarkan hasil tersebut diperoleh data tentang validitas dan reliabilitas perangkat pembelajaran sesuai tabel berikut.

Tabel 1. Validitas dan Reliabilitas SAP

\begin{tabular}{lccc}
\hline Satuan Acara Perkuliahan & Skor Validitas & Skor Reliabilitas & Keterangan \\
\hline SAP 1 - Hukum I \& II Newton & 3,55 & 98,57 & Valid dan Reliabel \\
\hline SAP 2 - Gaya Gesek & 3,65 & 95,94 & Valid dan Reliabel \\
\hline SAP 3 - Hukum III Newton & 3,30 & 94,94 & Valid dan Reliabel \\
\hline SAP 4 - Usaha Energi & 3,40 & 96,08 & Valid dan Reliabel \\
\hline SAP 5 - Energi Potensial & 3,75 & 98,65 & Valid dan Reliabel \\
\hline SAP 6 - Energi Kinetik dan & 3,45 & \multirow{2}{*}{91,86} & \multirow{2}{*}{ Valid dan Reliabel } \\
Hukum Kekekalan Energi & & & \\
\hline
\end{tabular}

Berdasarkan tabel di atas maka SAP yang dikembangkan layak digunakan dalam pembelajaran namun perlu adanya perbaikan berdasarkan saran-saran dari validator SAP, seperti: 1) indikator perlu lebih dijabarkan lagi dan sesuaikan dengan $\mathrm{K} 13,2$ ) tujuan pembelajaran lebih diperinci untuk pencapaian indikator pembelajaran, 3) kegiatan yang dilakukan dosen dalam setiap sintaks pembelajaran lebih detail dan disesuakian dengan alokasi waktu, dan 4) media pembelajaran yang digunakan harus disesuaikan dengan materi dan model pembelajaran agar tujuan untuk mencapai perubahan konseptual dengan memicu konflik kognitif dapat tercapai. Secara keseluruhan
SAP yang dikembangkan sudah layak dan bisa digunakan pada saat pembelajaran.

Lembar kegiatan mahasiswa (LKM) merupakan lembar panduan bagi mahasiswa yang dirancang oleh peneliti untuk menciptakan konflik kognitif dan menuntut mahasiswa untuk berpikir kritis dalam memecahkan masalah sehingga konflik kognitif yang terjadi dapat menuntun mahasiswa pada proses perubahan konseptual. LKM ini memuat rangkuman materi pelajaran, proses, alat dan bahan yang dibutuhkan, prosedur, tugas-tugas yang akan dikerjakan mahasiswa sesuai dengan topik yang dibahas. LKM ini sudah divalidasi oleh para ahli (expert) di bidang fisika dan pendidikan. 
Data hasil validitas dan reliabilitas LKM tersaji pada tabel berikuti.

Tabel 2. Validitas dan Reliabilitas LKM

\begin{tabular}{lccc}
\hline Satuan Acara Perkuliahan & Skor Validitas & Skor Reliabilitas & Keterangan \\
\hline LKM 1 - Hukum I \& II Newton & 3,30 & 91,45 & Valid dan Reliabel \\
\hline LKM 2 - Gaya Gesek & 3,45 & 91,86 & Valid dan Reliabel \\
\hline LKM 3 - Hukum III Newton & 3,55 & 95,71 & Valid dan Reliabel \\
\hline LKM 4 - Usaha Energi & 3,25 & 91,30 & Valid dan Reliabel \\
\hline LKM 5 - Energi Potensial & 3,55 & 91,91 & Valid dan Reliabel \\
\hline $\begin{array}{l}\text { LKM 6 - Energi Kinetik dan } \\
\text { Hukum Kekekalan Energi }\end{array}$ & 3,50 & 94,29 & \multirow{2}{*}{ Valid dan Reliabel } \\
\hline
\end{tabular}

Berdasarkan tabel di atas, diketahui semua LKM berkategori valid (V) dan reliabel sehingga layak digunakan dalam proses pembelajaran. Ada beberapa masukan pada LKM yaitu 1) aktivitas pada LKM harus lebih disesuaikan dengan model CCMCCA dan upayakan untuk dapat mencapai HOTS; 2) materi pada LKM harus sesuai RPP dan mampu menciptakan konflik kognitif; 3) dari segi bahasa sudah bagus namun alokasi waktu dengan kegiatan percobaan perlu diperhitungkan agar bisa tepat waktu.

Hasil kegiatan FGD ini menunjukkan bahwa SAP dan LKM yang dikembangkan sudah valid dan reliabel sehingga layak digunakan. Pengembangan perangkat pembelajaran berbasis CCM-CCA ini merupakan alternatif pembelajaran di abad 21 karena model pembelajaran CCM-CCA mampu memunculkan konflik kognitif yang akan membimbing peserta didik menuju perubahan konseptual sehingga pembelajaran yang dialami lebih bermakna. Pembelajaran dengan pendekatan konflik kognitif akan membuat Peserta didik banyak mengalami ketidakcocokan antara konsepsinya dengan fakta (konsep ilmiahnya), sehingga terjadi perubahan konseptual melalui proses asimilasi dan akomodasi pada saat pembelajaran dengan konflik kognitif [9][10]. Dalam suatu proses pembelajaran, untuk mendukung konflik kognitif yang dimunculkan oleh model pembelajaran CCM-CCA maka perlu menggunakan perangkat pembelajaran yang lebih spesifik sesuai karakteristik dari model yang digunakan. Pengembangan perangkat berbasis CCM-CCA ini sudah valid dan reliabel sehingga layak digunakan saat pembelajaran. Pemunculan konflik kognitif agar tercipta perubahan konseptual pada peserta didik akan lebih maksimal.

\section{KESIMPULAN}

Hasil analisis deskriptif terhadap validasi perangkat pembelajaran berbasis CCM-CCA menunjukkan bahwa perangkat pembelajaran berbasis CCM CCA valid dan reliabel serta sesuai dengan pembelajaran abad 21. Perangkat pembelajaran yang telah valid dan reliabel dapat dijadikan panduan dan acuan bagi pengajar dalam melaksanakan pembelajaran di kelas untuk membantu pebelajar dalam melakukan perubahan konseptual terhadap konsepsi konsepsi fisika yang salah menjadi konsepsi ilmiah (konsepsi fisikawan). Perangkat pembelajaran berbasis CCM-CCA ini dikembangkan untuk memaksimalkan kegiatan pembelajaran yang menggunakan model pembelajaran CCM-CCA karena model pembelajaran CCM-CCA ini dapat memunculkan konflik kognitif pada pebelajar.

\section{DAFTAR PUSTAKA}

[1] Makhrus, M. (2018). Validitas Model Pembelajaran CCM CCA. Jurnal Ilmiah Profesi Pendidikan, Volume 3, Nomor 1, Mei 2018: 62-66.

[2] Chi, M.T.H. (2008). Three types of conceptual change: Belief revision, mental model transformation, and categorical shift. In S.Vosniadou (Ed.), Handbook of research on conceptual change (pp. 61-82). Hillsdale, NJ: Erlbaum.

[3] Baser, M. (2006). Fostering conceptual change by cognitive conflict based instruction on students' understanding of heat andtemperature concepts. Eurasia Journal of Mathematics, Science, and Technology Education, 2 (2), 96-14, July 2006.

[4] Sagala, S. (2009). Konsep dan Makna Pembelajaran untuk Membantu Memecahkan Problematika Belajar dan Mengajar. Bandung: Alfabeta.

[5] Makhrus, M. (2018). Model Pembelajaran CCM CCA (Conceptual Change Model With Cognitive Conflict Approach). Mataram: Duta Pustaka Ilmu).

[6] Makhrus, M. (2018). Efektivitas Model Pembelajaran CCM CCA untuk Memfasilitasi Perubahan Konsep Gaya Pada Mahasiswa. Jurnal Pendidikan Fisika dan Teknologi Volume 4 No.2, Desember 2018: 253261.

[7] Nieveen, N. (1999). Prototyping to reach product quality. In Akker, J.V.D., Branch, R.M., Gustafson, K., Nieveen, N., and Plomp, 
T. (Eds.), Design Approaches and Toolsin Education and Training (pp. 125-135). Dordrecht, Netherlands: Springer.

[8] Gall, M.D. \& Borg. (2003). Educational Research. Boston: Pearson Education, Inc.

[9] Hidayatullah, Z., Makhrus, M., \& Gunada, I.W. (2018). Analisis Tingkat Kemampuan Berpikir Kritis Gelombang Mekaanik melalui Pembelajaran dengan Pendekatan Konflik Kognitif. Jurnal Pendidikan Fisika dan Teknologi, Volume 4 No. 2 , Desember 2018: 151-157.

[10] Cakir, M. (2008). constructivist approaches to learning in science and their implications for science pedagogy: A literature review. International Journal of Environmental \& Science Education, 3 (4), 193-206. 